\title{
"UROPATHOGENS": PREVALENCE AND ANTIBIOGRAM OF GRAM NEGATIVE BACILLI WITH SPECIAL REFERENCE TO EXTENDED SPECTRUM BETA LACTAMASE PRODUCTION
}

Vandana Berry, Madan Lal, Vidya Sagar, Rajesh Sawhney

1. Professor \& Head, Department of Microbiology. CMC \& Hospital, Ludhiana. Punjab.

2. Professor, Department of Microbiology. CMC \& Hospital, Ludhiana, Punjab.

3. Tutor, Department of Microbiology. CMC \& Hospital, Ludhiana, Punjab.

4. Professor, Department of Microbiology. Bhojia Dental College, Baddi, Himachal Pradesh.

\author{
CORRESPONDING AUTHOR \\ Dr. Vandana Berry, \\ Department of Microbiology, \\ CMC \& Hospital, Ludhiana, \\ Punjab -141 008. \\ E-mail:vandana_berry@yahoo.com \\ Ph: 00919463752244
}

ABSTRACT: This study was performed on culture and sensitivity of 6,951 urine samples, received in the Department of Microbiology, Christian Medical College \& Hospital, Ludhiana from out patients and in patients having urinary tract infection (UTI ).A total of 2,276 samples were found out to be culture positive, out of which 1,727 samples yielded gram negative organisms. Various isolates included 1,237 Escherichia coli (E. coli), 262 Klebsiella pneumoniae,47 Acinetobacter lwoffi, 39 Proteus mirabilis,39 Enterobacter aerogenes and 03 Pseudomonas aeruginosa. Extended spectrum beta lactamase (ESBL) production was studied in multidrug resistant E. coli. And Klebsiella pneumoniae, out of which $28.29 \%$ E.coli and 30.53\% Klebsiella pneumoniae yielded positive results. Our results suggest that the physician should be aware of high prevalence of ESBL producing E.coli and Klebsiella pneumonia which are the two common uropathogens, and should plan their therapy regime accordingly.

However, Acinetobacter species were mainly associated with nosocomial UTI whereas Enterobacter species were isolated mostly from out patients. Various uropathogens causing community acquired as well as nosocomial UTI showed poor response to cephalexin whereas resistant strains from both types of UTI exhibited good susceptibility to piperacillin/tazobactum combination.

KEY WORDS:-Pyelonephritis, Urinary tract infection (UTI), Escherichia coli (E.coli), Klebsiella pneumonia.

INTRODUCTION: Urinary Tract Infection (UTI) is defined as microbial invasion of the genitourinary tract. Normally kidneys, ureters, urinary bladder and proximal urethra are sterile, but distal urethra may carry bacteria derived from the faecal flora ${ }^{1}$. Most uropathogens gain access to the urinary tract via an ascending route but the continuous unidirectional flow of urine helps to minimize urinary tract infection ${ }^{2}$. UTI is divided into two broad categories i.e. lower UTI and upper UTI. Lower UTI is due to ascending infection caused by faecal coliforms and it includes urethritis, cystitis and prostatitis. Upper UTI means pyelitis (infection of the pelvis of kidney) and pyelonephritis (infection of the parenchyma of kidney). Pyelonephritis is generally caused by haematogenous spread. Females are more frequently affected by UTI 
because of short length of urethra and its proximity to anus. In males over 60 years of age, UTI due to enlarged prostate is relatively common. Some predisposing factors for UTI include pregnancy, urethral strictures / stones, prostatic hypertrophy, neurogenic bladder dysfunction following spinal cord injury or multiple sclerosis, reflux of urine from bladder up into ureters and sometimes into the renal pelvis and also some hereditary factors including presence of genetically determined receptors on uroepithelial cells. Many patients may remain asymptomatic. Gram negative bacteria are by far the most common infecting agents in the UTI. Therefore Gram negative uropathogens with their antibiotic susceptibility patterns are reported in the present study.

Current knowledge of the prevalent uropathogens with their antibiotic susceptibility is mandatory for the clinicians to provide appropriate treatment to the patients having UTI ${ }^{3}$.Broad spectrum beta lactamase producing organisms form a growing worldwide problem 4 . Antimicrobial resistance could happen by enzymatic inactivation, altered receptors or by defective antibiotic transport ${ }^{5}$. Extended spectrum beta lactamases hydrolyse broad spectrum Cephalosporins, which are being used commonly in the treatment of UTI.

MATERIALS AND METHODS: This retrospective study was conducted over a period of one year from 1st July, 2010 to30th June, 2011 in the Department of Microbiology, Christian Medical College \& Hospital, Ludhiana. A total of 6,951 mid stream urine samples were collected from in patients and out patients attending Christian Medical College and Hospital, Ludhiana. In patients were those patients who were admitted in the hospital with a complaint other than UTI but acquired UTI during their hospital stay. Out patients were those patients who were never hospitalised for the last one month and visited the out-patient department with complaint of UTI symptoms.

Taking all sterile precautions, these samples were inoculated on blood agar and MacConkey's agar using semi-quantitative method of inoculation. The culture plates were incubated at $37^{\circ} \mathrm{C}$ for 24 hours to 48 hours. After plating each urine sample was centrifuged at 3000 revolutions per minute for 3-5 minutes and the deposit was subjected to microscopy to look for the presence of pus cells, red blood cells, epithelial cells and bacteria. Isolates were identified by standard methods 6 . All the gram negative isolates were subjected to antibiotic sensitivity test by Kirby Bauer method 7 using various antibiotic discs from Hi Media namely Cephalexin (30 ug), Nalidixic acid (30ug), Amikacin (30ug), Ceftriaxone (30ug), Ciprofloxacin (5ug), Norfloxacin (10ug) and combined Piperacillin / Tazobactam (100/10ug).

E.coli and Klebsiella pneumoniae were examined for ESBL production by Double Disc Synergy Test ${ }^{8}$. Ceftazidime (30ug), Cefotaxime (30ug), Ceftriaxone (30ug) and Aztreonam (30ug) discs were placed $25 \mathrm{~mm}$ centre to centre away from a 20 ug Amoxicillin/10ug Clavulanate disc.The plate was incubated at $37^{\circ} \mathrm{C}$ overnight under aerobic conditions and observed for enhancement of the Ceftazidime zone of inhibition near the Amoxycillin-Clavulanic acid disc producing a keyhole appearance.

RESULTS: A total of 6,951 urine samples, which included 3,407 samples from out patients and 3,544 samples from in patients, were tested for bacteriological growth.The number of positive samples were 2,276 (32.74\%), out of which 1,727 (75.88\%) samples showed Gram negative organisms as indicated in Table 1. Escherichia coli showed $24.75 \%$ ESBL production from out and $33.00 \%$ from in patients, whereas Klebsiella pneumoniae showed $29.41 \%$ ESBL production from outdoor and $31.46 \%$ from in patients. Amongst various uropathogens isolated, E.coli 
emerged as the commonest isolate forming $71.63 \%$ of the population $(1,237 / 1,727)$. Enterobacter $(2.26 \%)$ was mainly responsible for community acquired UTI. Pseudomonas aeruginosa (5.96\%) was mainly associated with hospital acquired UTI. Different isolates exhibited varying sensitivity pattern with nosocomial pathogens showing comparatively higher resistance as depicted in Table 2.

DISCUSSION: Urinary tract infection continues to be one of the most frequently diagnosed conditions in the patients presenting to the primary care practitioner. It is important because of the constantly shifting landscape of drug resistance and antibiotic options ${ }^{9}$. UTI is the third most important common cause of hospital visits in India ${ }^{10}$. Most antibiotics are prescribed as empirical therapy before either the identification of pathogen or its antibiotic sensitivity. Although the spectrum of isolates remains constant, their antibiotic sensitivity pattern varies from place to place and even amongst community based and nosocomial isolates over one geographical region. In a study conducted in AIIMS, New Delhi, from July 1998 to June 1999, Mandalet al ${ }^{11}$ reported E.coli to be the commonest urinary pathogen accounting for $45.5 \%$ of the community acquired UTI in urban slums of South Delhi. In our study also E.coli remains the dominant pathogen with $48.98 \%$ isolates in community acquired UTI and $51.02 \%$ isolates in hospital acquired infections. Escherichia coli and Klebsiella pneumoniae constitute the major population of uropathogens.

In the hospitalized patients iatrogenic UTIs following catheterisation constitute a fair proportion with commensals and saprophytes as usual aetiological agents profile of urinary tract isolates. In the present study Klebsiella pneumoniae isolates were $45.42 \%$ and $54.58 \%$ in community related and hospitalized patients respectively. Acinetobacter lwoffi was more common in hospital acquired infections, Enterobacter aerogenes was found out to be more prevalent as a community based uropathogens and Proteus mirabilis is present in almost equivalence in both the kinds of UTI cases. Pseudomonas aeruginosa is a common cause of urinary tract infection in hospitals following instrumentation, surgery or catheterization of the urinary tract, often in patients recently treated with antibiotics. Hence it is more common as a nosocomial uropathogen as compared to its prevalence in causing community based UTI. In the present study there were $74.75 \%$ Pseudomonas aeruginosa isolates associated with hospital acquired UTI.

Extensive use as well as misuse of antibiotics is the primary cause for change in the antimicrobial sensitivity profile of urinary tract isolates. In the present study marked degree of resistance was observed towards Cephalexin and Nalidixic acid. Piperacillin/ Tazobactam combination was found the most efficient agent followed by Amikacin. The community based isolates have exhibited better antimicrobial susceptibility pattern as compared to that shown by the nosocomial pathogens. As such it becomes important for the clinical practitioners to know about the common prevailing urinary pathogens in the hospital as well as in the community along with their likely antimicrobial susceptibility and resistance patterns. In a study conducted by Sader et al ${ }^{12}$ Cefotaxime was found to be quite effective against E.coli ( $98.70 \%$ susceptibility). In our study also a third generation cephalosporin i.e Ceftriaxone was found to be $92.90 \%$ and 85.95\% effective towards community based and hospital acquired E.coli respectively.

Hereby we conclude that hospital acquired pathogens are different and more resistant to various drugs as compared to community based pathogens. These should be treated specifically after antimicrobial testing following culture of urine samples. 


\section{REFERENCES:}

1. Baveja CP,Urinary tract infection. In : Text book of Microbiology. 2nd Ed, Arya Publications, 2005 : 564-67.

2. Aggarwal KK, Bajpai $\mathrm{V}$., The Role of cefpodoxime in respiratory tract, urinary tract, skin and soft tissue infections. Ind J Clin. Practice $2005 ; 16(3): 29-32$

3. GrubenbergGN.. Antibiotic Sensitivity of Urinary Pathogens 1971-1982. Antimicrob chemother1984;14:17-23.

4. LivemoreDM. Beta Lactamases in Laboratory and Clinical Resistance. Clin Microbial Rev.1995;8:557-84.

5. Koneman EWet al.Antimicrobial Resistance, color atlas and color book of Diagnostic Microbiology,FifthEdition,USA-Philadelphia,Lipponcot Raven Publishers 19976;15:798800.

6. ColleeJG,DugaidJP,Fraser AG. Marmion BP.Tests for identification of bacteria.Mackie and McCartney's Practical Medical Microbiology 13th Ed. Vol.2. Edinburgh: Churchill Livingstone, 1989; 141- 60.

7. Bauer AW, Kirby WMM, Sherris JC, TurckM. Antibiotic susceptibility testing by a standardized single disk method. AM J ClinPathol 1966; 45: 493-96.

8. National Committee for Clinical Laboratory Standards. Performance standards for Antimicrobiol Disc Susceptibility test. Sixth edition: NCCLS, Villanova, PA. 1997 Approved Standard M2-A6.

9. Sharma B, Mital V, Singh P, Nanda R, Chavda RK, Moharana AK.

Prospective multicentric epidemiological survey of the prevalence and antimicrobial susceptibility of the urinary tract pathogens. The Ind. Practioner, 2003 ; 56 (4) $237-44$.

10. Shroff KJ, JadavSK, MehtaNH, Acharya VN. Bacteriology of UTI in hospitalized and non-hospitalized patients. J Assoc Physicians Ind 1979; 27; 84-88.

11. Mandal P, Kapil K, Goswami, Dass B, Dwivedi SN. Uropathogenic Escherichia coli causing urinary tract infections. Ind J Med Res. $2001 ; 114: 207$ - 11.

12. Sader HS, Biedenbach DJ, Streit JM, Jones RN. Cefdinir activity against contemporary North American isolates from community acquired urinary tract infections. Int JAntimicrob. Agents 2005; 25(1):89-92.

Table 1 Isolated Uropathogens

\begin{tabular}{|c|c|c|c|c|c|}
\hline $\begin{array}{l}\text { ORGANISMS } \\
\text { Isolates }\end{array}$ & Total & $\begin{array}{l}\text { OUT PATI } \\
\text { No. } \\
\text { Percentag }\end{array}$ & (ESBLProducer) & $\begin{array}{l}\text { IN PATIENT } \\
\text { No. } \\
\text { Percentage }\end{array}$ & (ESBLproducer) \\
\hline Escherichiacoli & 1237 & $\begin{array}{l}606 \\
48.98\end{array}$ & $(150)$ & $\begin{array}{r}631 \\
51.01\end{array}$ & $(200)$ \\
\hline Klebsiella peumoniae & 262 & $\begin{array}{c}119 \\
45.42\end{array}$ & (35) & $\begin{array}{r}143 \\
54.58\end{array}$ & $(45)$ \\
\hline Pseudomonas aeruginosa & 103 & $\begin{array}{r}26 \\
25.25\end{array}$ & & $\begin{array}{c}77 \\
74.75\end{array}$ & \\
\hline
\end{tabular}




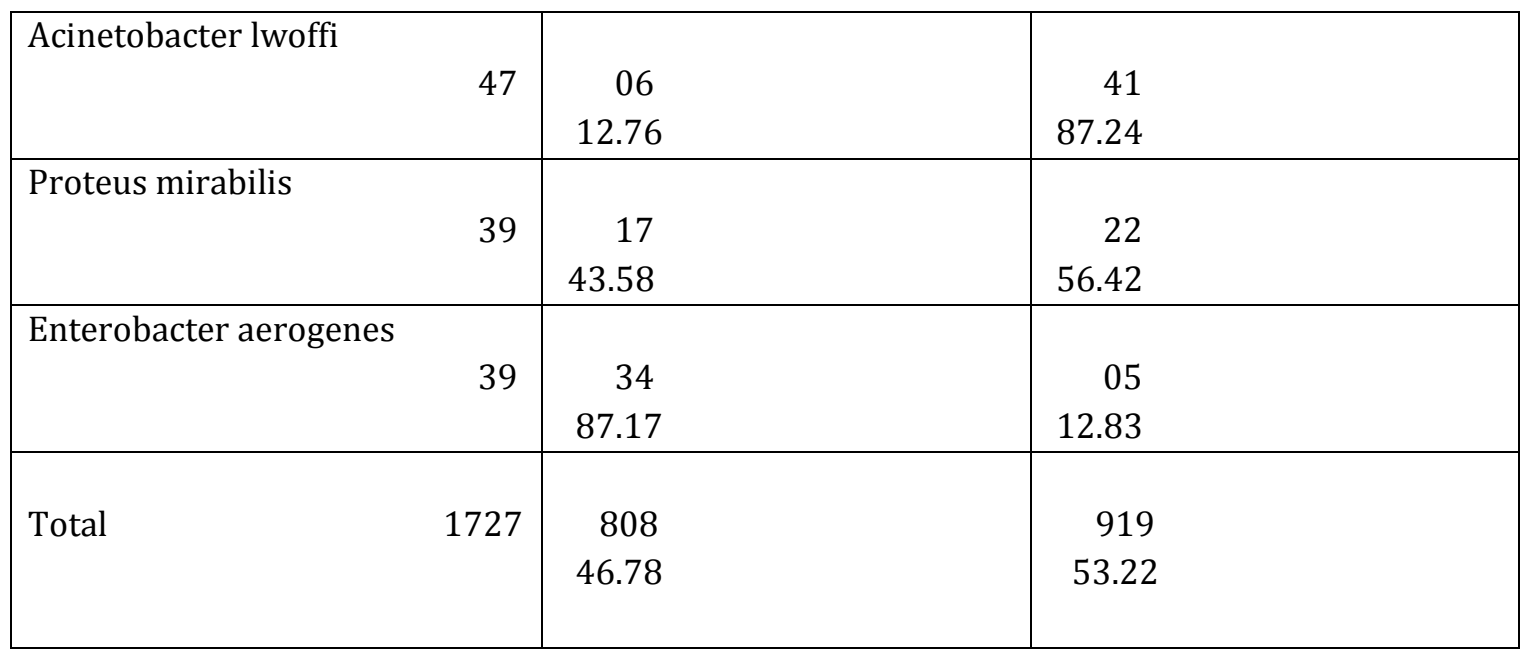

Table 2 Antibiotic Sensitivity Pattern of Uropathogens in Percentage

\begin{tabular}{|c|c|c|c|c|c|c|}
\hline $\begin{array}{l}\text { ORGANISM } \\
\text { ANTIBIOTIC }\end{array}$ & $\begin{array}{l}\text { E.coli } \\
\text { CA } \\
\text { HA }\end{array}$ & $\begin{array}{l}\text { Klebsiella } \\
\text { CA } \\
\text { HA }\end{array}$ & $\begin{array}{l}\text { Pseudomonas } \\
\text { CA } \\
\text { HA }\end{array}$ & $\begin{array}{l}\text { Acinetoba } \\
\text { cter } \\
\text { CA } \\
\text { HA }\end{array}$ & $\begin{array}{l}\text { Proteus } \\
\text { CA } \\
\text { HA }\end{array}$ & $\begin{array}{l}\text { Enterobacter } \\
\text { CA } \\
\text { HA }\end{array}$ \\
\hline CEPHALEXIN & $\begin{array}{l}22.60 \\
10.11\end{array}$ & $\begin{array}{l}63.86 \\
50.4\end{array}$ & $\begin{array}{c}42.31 \\
19.48\end{array}$ & $\begin{array}{l}66.67 \\
60.98\end{array}$ & $\begin{array}{l}64.71 \\
54.54\end{array}$ & $\begin{array}{c}79.41 \\
60\end{array}$ \\
\hline $\begin{array}{l}\text { NALIDIXIC } \\
\text { ACID }\end{array}$ & $\begin{array}{l}24.25 \\
21.61\end{array}$ & $\begin{array}{l}73.08 \\
65.03\end{array}$ & $\begin{array}{l}57.69 \\
20.78\end{array}$ & $\begin{array}{l}83.33 \\
75.61\end{array}$ & $\begin{array}{l}82.32 \\
77.18\end{array}$ & $\begin{array}{c}70.56 \\
60\end{array}$ \\
\hline AMIKACIN & $\begin{array}{l}96.36 \\
78.53\end{array}$ & $\begin{array}{l}89.88 \\
88.81\end{array}$ & $\begin{array}{l}79.82 \\
37.66\end{array}$ & $\begin{array}{c}100 \\
100\end{array}$ & $\begin{array}{l}94.08 \\
81.72\end{array}$ & $\begin{array}{c}100 \\
85.26\end{array}$ \\
\hline CEFTRIAXONE & $\begin{array}{l}92.90 \\
85.95 \\
\end{array}$ & $\begin{array}{l}93.24 \\
90.21 \\
\end{array}$ & $\begin{array}{l}84.61 \\
44.15\end{array}$ & $\begin{array}{r}83.33 \\
82.93 \\
\end{array}$ & $\begin{array}{l}88.23 \\
86.26 \\
\end{array}$ & $\begin{array}{c}100 \\
85.26\end{array}$ \\
\hline $\begin{array}{l}\text { CIPROFLOXAC } \\
\text { IN }\end{array}$ & $\begin{array}{l}82.01 \\
63.99\end{array}$ & $\begin{array}{l}80.64 \\
67.93 \\
\end{array}$ & $\begin{array}{l}46.15 \\
27.31 \\
\end{array}$ & $\begin{array}{c}83.33 \\
75.61 \\
\end{array}$ & $\begin{array}{l}77.18 \\
64.71 \\
\end{array}$ & $\begin{array}{c}100 \\
94.11\end{array}$ \\
\hline NORFLOXACIN & $\begin{array}{l}39.11 \\
37.92\end{array}$ & $\begin{array}{l}85.68 \\
65.17\end{array}$ & $\begin{array}{l}34.61 \\
31.22\end{array}$ & $\begin{array}{c}100 \\
97.56\end{array}$ & $\begin{array}{l}76.44 \\
77.18\end{array}$ & $\begin{array}{c}100 \\
88.23\end{array}$ \\
\hline $\begin{array}{l}\text { PIPERACILLIN } \\
\& \\
\text { TAZOBACTAM }\end{array}$ & $\begin{array}{l}98.84 \\
92.27\end{array}$ & $\begin{array}{l}98.28 \\
97.90\end{array}$ & $\begin{array}{l}96.15 \\
89.71\end{array}$ & $\begin{array}{c}100 \\
100\end{array}$ & $\begin{array}{l}100 \\
77.18\end{array}$ & $\begin{array}{c}100 \\
100\end{array}$ \\
\hline
\end{tabular}

CA-Community Acquired

HA-Hospital Acquired 